\title{
Study on the Cost Management of SMEs
}

\author{
Yuan Qian ${ }^{1}$, Yan Wan $^{2}$ \\ ${ }^{1}$ Nanchang Institute of Science \& Technology, Nanchang, Jiangxi, 330108
}

KEYWORDS: SMEs; Cost Management; Enterprise Operation

\begin{abstract}
Strategic cost management is a strategic management and cost management of a combination product, strategic cost management to produce, on the one hand adapted to the needs of strategic management, on the other hand is the traditional enterprise cost management change. as the main force of the high-speed national economic growth, China's SMEs are the complexity of the economic environment in which internal and external cost pressures facing the urgent need to adopt a new business concept of strategic cost management, while operating characteristics of SMEs in turn determines the strategic cost management theory in the feasibility and necessity of SME applications. Purpose of this paper is to try to provide SMEs with new advanced cost management methods, to enable SMEs in strengthening the level of cost management while obtaining a competitive advantage.
\end{abstract}

\section{Introduction}

In recent years, due to the mismanagement cost the company many examples of closure of enterprises, cost management has become the focus of competition has made absolute, and increasing attention has been paid. CCTV "economic half-hour" at December 10, 2007 reported the Pearl River Delta thousands of small and medium enterprises closed down or relocated due to rising costs. In the Pearl River Delta, mostly labor-intensive industries, these enterprises were faced with the situation of closure or relocation of these SMEs, competitive pressures from sharply rising raw material costs, power costs and rent. In addition, relying on cost management also win examples. 1997 Asian financial crisis, many Korean companies have been difficult to maintain. At this time Samsung has nearly $\$ 18$ billion debt, which is about three times more than the company's net assets at the critical moment on the verge of collapse, Samsung has been to challenge the limits of the formula to reduce costs, the savings extend to every detail, so that the financial crisis stood up again, and the development of today's well-known enterprises. Thus, the costs related to the survival of the enterprise management can save companies in distress. Since SMEs have a huge space for development, so in the beginning of the development of the need to strengthen cost management efforts, and improve cost management system can take the cost of the introduction of advanced management concepts and scientific management methods, and gradually tap the potential to reduce costs, resulting in fierce competition in the market come to the fore. Traditional cost management objectives will be limited to minimize costs and maximize profits, which is a new type of strategic cost management objectives contrary, thus impeding the vision of managers. China is the world's fastest growing countries, has a very active market environment, small and medium enterprises in order to maintain sustainable development of power in the fierce competition in the market, it is necessary to explore the optimal cost management.

\section{Situation of SMEs Management Costs}


Cost management an important role in the internal management of small and medium enterprises in, reflecting the need for cost management, cost management but SMEs but there are many obvious problems, the cost of managing the status quo is not optimistic. Mainly in the following aspects:

A member of the SME internal cost management is not strong sense of ownership and many employees believe that only costs related to the management of the interests of business owners, the only question to be considered leaders, and what does not, so do not actively participate in the process of cost management. Employees as a corporate cell populations, businesses have a future, is there a future employees, employees should be based on a sense of ownership involved in cost management, the development of business contacts and personal value of life together; at the same time also on the staff of the enterprise cost management reward the contribution made, it shows that the main business of cost management should also be business owners and staff. Cost management ignored the needs of micro enterprises and economic management is a cost associated power cost management also from internal management purposes, but as a business cost management body does not recognize this, cost management only limited to the observance and implementation of national laws and regulations, we need only focus on the macro-management of cost, no cost information as a basis for strategy development, ignoring the importance of cost management for enterprise management. Value chain analysis of the industry value chain analysis is not sufficient to create value refers to a series of activities of the enterprise in order to determine the competitive advantage occurs when customers use value of production of products or services. Any activity that has the potential to add value to the final product, the industry chain of any company's production activities are likely to add value to the final product. Value chain analysis is carried out on the basis of the industrial chain on tap all potential sources of potential value for the enterprise cost management to find a breakthrough. Some SMEs only focus on internal value chain analysis, the overall value chain analysis allowed to grasp, which often leads to cost drivers do not dig deep, limited efforts to control costs, hindering the establishment of enterprise cost strategic advantage, weakening the long-term development of enterprises. Therefore, enterprises should cost management issues into consideration of the industry environment, the use of the whole value chain analysis to develop enterprise development strategies, we can ensure the realization of corporate strategic objectives. Cost Management. Cost management has obvious short-term behavior of many SMEs simply to reduce the amount of costs, considering only affect the cost of a particular accounting period, the pursuit of short-term benefits, no cost analysis for each accounting period constituted no research products reaction into the market, and there is no more cost-benefit analysis, resulting in a disjointed cost management goals and business strategy. Meanwhile, some corporate executives mobility is relatively large, in order to achieve high performance during his own tenure, wanton reduce the cost of investment, focus only on short-term benefits, without considering the long-term development needs of enterprises, making cost information at all stages of not comparable sex, production technology has not been effectively improved and improved. Furthermore, the absence of some enterprises to establish a sound system of cost accounting management, implicated each other between the various agencies and positions, there is no breakdown of the cost estimates to the various departments, the lack of effective incentive and restraint mechanisms, which cannot fully mobilize personnel and business management all employees cost management, and improving economic efficiency initiative.

\section{Problems of SMEs Cost Management}

SMEs in China can be seen from the discussion of cost management methods and content of cost management, there are many problems, which lead to poor operation of the market effect, 
weakening the competitiveness of enterprises, unsustainable development and market competition, mainly due to the following points: a, cost management cost management theory, although the lag experienced its infancy, experience management, scientific management, modern management and strategic management stage, but did not seriously study Chinese SMEs connotation of cost management in and learn only ask for reference, not for exploration, not the theory and practice of business combination. Enterprise cost management in evaluating the effect of the level of the cost as a simple assessment criteria, such isolated judge sided only reduces the cost of data, for enterprises to obtain long-term competitive advantage strategy cannot play a positive role in promoting. b, cost management and the external economic environment does not fit today's production is no longer a production-oriented, but the market-oriented, which determines the power needs of the market is the organization of production, what the market needs and what it there is room for development. Enterprises must be put into operation at the beginning, in-depth market research and products design departure from the consumer demand, avoiding excess resources due to product features or mismatched brought consuming. In the production process, but also concerned about the development of technology and market changes, improve business efficiency and accurate cost prediction, control and accounting, a comprehensive assessment and analysis of changes in the cost. c, quality managers of SMEs is not high, many old ideas SME managers still retains "on the cost of Cost" narrow understanding, no conversion outdated concept, simple to manage their own businesses as a cost object, from the market economy this environment. Market economy requires companies to suppliers, vendors and even competitors are included in the cost of managed objects being can significantly reduce business costs by analyzing the upstream and downstream products and services features, even with the upstream and downstream enterprises to reduce costs. In addition, SMEs, due to weak market regulation, binding is not strong, the lack of proper internal check system, cost management and control work is not standardized, so that strategic cost management does not achieve the desired results.

\section{Frame Design of Strategic Cost Management Model}

Either the cost model, the environment has its growth and development, are also in accordance with certain principles developed, strategic cost management is also true, a, any enterprise to adapt to environmental principles in a certain environment are among the economic environment, social environment, international environment, value chain environment, industry environment and so on, not man can control the economic environment and changes in the corporate environment can not only adapt to the changing environment, environmental factors can affect the strategic choice of enterprises, business objectives and direction of development. Strategic objectives of the enterprise must be based on objective reality, the process of cost management should pay attention to coordinating its environment. The principle of long-term development strategy of cost management main purpose is to develop long-term business growth and, unlike in the past to pursue short-term interests of management objectives. Enterprises to maintain a sustained growth and development, they must create their own competitive advantage, build competitive advantage by reducing costs and to be an appropriate increase in costs through product differentiation to achieve. Construction of Strategic Cost Management application model should be based on a strategic height, look to the future, and value chain enterprises to form a community of interests, to achieve win-win situation. Logically consistent principle of strategic cost management model is the most important goal is to use rigorous theoretical and practical framework to guide cost management, scientific theories must be well-structured, logical, consistent, and there must be a logical derivation between the front and rear link relationship. Strategy is a process, during all stages is indispensable. Develop a good 
strategy is often gradually penetrate from the outside to the inside. Construction of strategic cost management mode also must strictly abide by thinking outside to the inside logic theory and methodology, progressive approach. $d$, the overall best principles of corporate management is a never-ending process, huge profits is not a day in January, a year can get the target cost management than on strategic enterprises have become the monopoly operator, and the cost advantage obtained not insurmountable, but it will make the business competitors cannot imitate counterattack. Companies to maintain their competitive advantage must be coordinated with the development of enterprise value chain together while avoiding disadvantages, risk-sharing, creating a win-win future. e, the principle of involvement of strategic cost management is a global task, from strategy formulation to implementation of the plan, from cost control to the feedback information, the whole process including business leaders, management and employees. In the implementation process of strategic cost management, each level has its role, business leaders need to develop strategies to implement and monitor the management, executive management also need employee feedback. $\mathrm{f}$, the feedback correction principle to any one of the system are in the application process of continuous improvement and constantly improve, to build strategic cost management mode is not achieved overnight. Time span enterprise strategic management is generally more than five years, industry factors, environmental factors, market factors, the changing international factors, the need for application keeps track of feedback correction mode, in order to make strategic cost management mode reasonable and effective.

\section{Conclusion}

In an increasingly competitive market today, some of the cost of traditional concepts and methods faced with enormous challenges and strengthen the theory and practice of cost management is imperative. Strategic cost management as an advanced cost management methods, it retains the advantages of the traditional cost management while improving the shortcomings of traditional cost management methods and innovative in other ways, its history so far, only 20 years as a new thing, and many of its own immaturity and imperfections. How to enrich and improve the strategic cost management, cost management and advanced concepts and technical analysis tools used in practice as a strategic cost management research and extension priorities.

\section{Reference:}

[1] M. Bromwish. The Case for Strategy Management of Accounting:. The Role of Accounting Information for Strategy in Competitive Markets Accounting, Organization and Sciety.2001, (15), 97-102.

[2] Jack Shank, V Govindaraan Strategic Cost Management: The new tool for competitive advantage. Free Press. 1993. 41-45.

[3] Capaldo, Guido The Evaluation of Innovation Capabilities in Small Software Fimrs: A Methodological Approach. Small Business Economics. Dee. 2003. 72.

[4] Simmonds K. Strategic Management Accounting [J]. Management Accounting (UK). 1981 (59), 54.

[5] Charles W. L. Hill, Gareth R. Jones. Strategic Management [M]. The China MarketPress.2008.43-44. 